Research Article

\title{
Evolutionary Game Research between the Government Environmental Regulation Intensities and the Pollution Emissions of Papermaking Enterprises
}

\author{
Sen Zhang $\mathbb{D}^{1},{ }^{1}$ Guangyuan Qin $\mathbb{D}^{1},{ }^{1}$ Ling Wang, ${ }^{2}$ Baodong Cheng, ${ }^{1}$ and Yuan Tian $\mathbb{D}^{2}$ \\ ${ }^{1}$ School of Economics and Management, Beijing Forestry University, Beijing 100083, China \\ ${ }^{2}$ Business College, Beijing Union University, Beijing 100025, China \\ Correspondence should be addressed to Guangyuan Qin; qinguangyuan1107@126.com
}

Received 1 June 2021; Revised 3 August 2021; Accepted 16 August 2021; Published 9 September 2021

Academic Editor: Daqing Gong

Copyright (c) 2021 Sen Zhang et al. This is an open access article distributed under the Creative Commons Attribution License, which permits unrestricted use, distribution, and reproduction in any medium, provided the original work is properly cited.

Environmental regulations of different intensities may have different impacts on polluting enterprises. The purpose of this article is to analyze how different environmental regulations affect the pollution discharge strategies of papermaking enterprises. By establishing an evolutionary game model between the government environmental regulation intensities and the pollutant emissions from papermaking enterprises, this thesis further solves the model and performs stability analysis and finally uses MATLAB to conduct simulation studies. And the researching results show that papermaking enterprises will take risks to choose the illegal pollutant discharge strategies when the illegal profits are large. Further analysis shows that the increase in the successful probability of the strong environmental regulations does not necessarily force papermaking enterprises to choose to comply with pollution discharge regulations. However, papermaking enterprises may choose to comply with discharge pollution regulations not only by increasing the successful probability of strong environmental regulations but also by increasing the rewards and punishments for papermaking enterprises as well as by increasing the probability of reporting violations of pollutants. Based on the above results, the author proposes several countermeasures, such as establishing a specialized pollution monitoring agency, encouraging third-party supervision, reporting pollution behaviors, and increasing penalties for polluting companies for violations. China is in a critical period of transition from rapid development to high-quality development. It will provide some reliable references for the construction of a green economy and an ecological economy that the characteristics and relationships between the intensity of government environmental regulations and corporate pollution emissions revealed in this article.

\section{Introduction}

When the economy developed into the post-industrial era, the environmental pollution had become a problem that people had to face on the road of economic development. According to the China Statistical Yearbook, China's wastewater discharge in 2005 was 24,311.21 million tons. And in 2015, China's total waste water discharge was $73,532.27$ million, with an average annual growth rate of $9.7 \%$. What is more, the cost of environmental pollution treatment accounted for China's annual average $8 \%-15 \%$ of GDP [1]. Among which, the papermaking enterprises discharged 2,366.84 million tons of wastewater in 2015, accounting for $3.2 \%$ of the total national wastewater discharge.
It can be seen that the discharge of pollutants from the papermaking enterprises is still the worst-hit area of environmental pollution. To reduce the negative impact of environmental pollution on economic development, government-led environmental regulations have emerged as a means of integrating economic, administrative, and legal forms and to reduce environmental pollution. To a certain extent, the implementation of environmental regulatory policies has reduced the discharge of pollutants from the papermaking enterprises. However, the intensity of environmental regulations can vary greatly. So, it still needs further exploration how to better clarify the relationship between the intensity of government environmental regulations and corporate pollution emissions. 
When studying the intensity of government environmental regulations and corporate pollution emissions, it was necessary to fully consider the changes in the intensity of environmental regulations and the successful probability of the different environmental regulations. In addition, it was also needed to consider the conflict of interest between the two parties in the game [2]. Based on the above facts, it can be seen that, as the worst-hit area of pollutant discharge, papermaking enterprises will inevitably be affected by different environmental regulatory intensities. And it is still needed to be further explored how different environmental regulatory intensities affect the choice of corporate pollutant emission strategies. By constructing evolutionary game models, many scholars have analyzed the strategic choices between environmental regulations and corporate pollution. However, most scholars mainly focused on whether corporate pollution will be affected by environmental regulations [3-5]. And few scholars considered the problem of different environmental regulatory intensities and the successful probability of different environmental regulatory intensities. Under normal circumstances, different environmental regulation intensities will cause polluting companies to choose different pollution emission strategies. And the successful probability of different environmental regulation intensities will also affect the pollution emission strategies of polluting companies. By further considering the changes in the government environmental regulation intensities and the successful probability of different environmental regulation intensities, this thesis uses evolutionary game theory, to study the strategy choices of the government and polluting companies in different situations. In-depth analysis of the environmental regulation intensities and the strategic choices between polluting companies has certain practical guiding significance for the government to formulate environmental policies.

The structure of this thesis is as follows. Section 2 reviews the relevant literature and analyzes the mechanism of the impact of the environmental regulation intensities on corporate pollution emissions. Section 3 proposes hypotheses and establishes the game payment matrix. Section 4 establishes the evolutionary game model, solves the problem, and analyzes the stability. Section 5 carries out the simulation analysis of the evolutionary game model. Section 6 gives out the research conclusions and suggestions and further discusses the research conclusions.

\section{Literature Review and Mechanism Analysis}

2.1. Literature Review. The purpose of this thesis is to study the impact of environmental regulation intensities on the pollution discharge strategies of the papermaking enterprises. By introducing different environmental regulation intensities and the successful probability of different environmental regulation intensities, an evolutionary game model is established to analyze the behaviors of the players of the game. The literature related to this research mainly involves the game between the government and polluting companies and the impact of the environmental regulation intensities on polluting companies. This thesis reviews the existing literature from the following two aspects.

Consider the game between the government and polluting companies. Researches on the game between the government and polluting companies can be roughly divided into three categories: cost control, revenue rewards and punishments, and third-party participation. As far as cost control was concerned, in the game between the government and polluting companies, whether the government monitors environmental pollution depended on the size of its monitoring cost [6]. Reducing the rent-seeking costs and governance costs of polluting companies enabled soil polluting companies to reduce pollution [7]. Cutting lowcarbon production costs and reducing government supervision costs were the keys to power enterprises to reduce carbon dioxide emissions [8]. Reducing the cost of supervision increased the enthusiasm of government supervision, which further enhanced the effectiveness of supervision and enable shipping companies to reduce pollution emissions [9]. Of course, increased subsidies for companies to implement cleaner production would also enable companies to reduce pollutant emissions and choose cleaner production strategies [10,11]. Similarly, reducing the cost of government supervision would also strengthen the government supervision, which in turn would lead to a reduction in corporate pollution emissions [12]. As far as revenue incentives were concerned, if the government's incentive level and monitoring frequency were under certain conditions, companies would often control pollution after long-term repeated gaming [13]. As the compliance incentives increased, local governments would more effectively implement environmental regulations and further improve environmental quality $[14,15]$. Similarly, increasing the revenue of government departments would also enable the government to increase its supervision, thereby reducing corporate pollution emissions [16-18]. In terms of revenue penalty, increased penalties by the government would enable offshore mining companies to reduce pollution [19]. By establishing a dynamic penalty mechanism and increasing the penalty coefficient, the government would enhance the effect of environmental regulations and enable polluting enterprises to reduce emissions [20-22]. The government's increase in penalties on enterprises would increase the cost of violations of the law, and the increase in the cost of violations would lead to the reduction of waste gas emissions by enterprises, which in turn would enable the government to achieve effective long-term supervision [23, 24]. Similarly, increasing the loss of the higher level government's inaction was an important guarantee for effective supervision $[25,26]$. As far as third-party participation was concerned, with the increase in public participation and the increase in the probability of reporting illegal emissions from enterprises, enterprises were more inclined to choose to actively reduce pollutant emissions [27]. Whether the public, as a third party, can play an effective supervisory role depended on the size of the supervisory power of the higher level government [28]. The establishment of a contractual governance system by the government and a third party was also an important means to reduce corporate pollution [29]. 
Consider the impact of the environmental regulation intensities on polluting companies. There were still major controversies about the existing researches on the impact of environmental regulation intensities on polluting enterprises. One view was that with the increase in the environmental regulation intensities, the emissions of enterprises would be reduced. With the increase in the environmental regulation intensities and other external pressures, $61.2 \%$ of heavily polluting enterprises would be more inclined to adopt relatively conservative environmental behaviors [30]. At the same time, with the strengthening of environmental regulations, carbon emissions could be significantly reduced. What is more, high-intensity environmental regulations could also reduce carbon emissions by influencing technological innovation [31]. In addition, strengthening the intensity of environmental regulations could significantly reduce the intensity of environmental pollution [32,33]. Another view was that the increase in the intensity of environmental regulations did not have an obvious linear impact on corporate pollutant emissions. Whether it was a fee-based environmental regulation or an investment-based environmental regulation, both had a nonlinear impact on environmental pollution [34]. Moreover, under the constraints of Internet penetration rate, the impact of environmental regulation intensities on corporate pollution emission intensities presented an obvious inverted " $U$ "-shaped characteristic [35].

Through analyzing the existing literature, it can be found that most scholars do not consider the changes in the environmental regulation intensities in the game analysis between the government and the polluting enterprises. And the studies that consider the changes in the environmental regulation intensities are mostly empirical studies. In addition, in analyzing the games between the government and polluting enterprises, scholars ignore the successful probability of different environmental regulatory intensities and the probability of the polluting enterprises being reported for violations. Compared with the existing researches, the main marginal contributions of this research are as follows:

(1) This study not only considers the changes of the government environmental regulation intensities but also considers the successful probability of different environmental regulatory intensities and the reporting probability of the polluting companies' illegal emissions. On this basis, it further analyzes how the players of the game make strategic choices under the assumption of bounded rationality.

(2) On the basis of (1), this study uses MATLAB to numerically simulate the government environmental regulation intensities and the evolution path of polluting enterprises. And further analyzes the influence of environmental regulation intensities on polluting enterprises' pollution emission strategies under different initial values.

(3) Through evolutionary game and numerical simulation analysis, the key factors that affect the strategy choices of the game player are obtained. Increasing the rewards for compliant pollutant discharge will make papermaking enterprises choose conservative pollutant discharge behaviors. Meanwhile increasing the penalties for illegal pollutant discharge will cause papermaking enterprises to choose compliant pollutant discharge. And increasing the reporting probability of the papermaking enterprises' violations of pollutant discharge will make the papermaking enterprises choose to comply with regulations to discharge pollutants.

2.2. Mechanism Analysis. As mentioned earlier, the author believes that environmental regulations are not only divided into strengths and weaknesses but also whether they can be realized, that is, after the implementation of environmental regulations, how likely they will achieve their ultimate goals. In addition, the supervision of higher level governments and other social members may be another important factor in the realization of environmental regulations. The specific mechanism diagram is shown in Figure 1.

It can be clearly seen in Figure 1 that when the government implements high-strength environmental regulation policies, the paper papermaking enterprises will have two choices at this time. One is to comply with the regulations, that is, to comply with the government policies and reduce pollutant emissions. The other is noncompliance, that is, against the government's policies and continue to emit the same amount of pollutants as before. Which strategies to choose depends not only on the papermaking enterprise's own interests but also on government rewards and penalties. If papermaking enterprises choose to comply with the regulations, the government rewards are far greater than the cost of compliance, then papermaking enterprises will choose to comply with the regulations. On the contrary, if the government gives less rewards, the papermaking enterprises are likely to choose not to comply. Conversely, when the government implements lower-strength environmental regulations, papermaking enterprises will have the same two choices. If papermaking enterprises choose to abide by the regulations, the government is likely to be detected by the higher level government for negligence and then maybe fined. If both parties choose not to perform their duties, both parties may be detected by the higher level government or other social members and suffer losses. One thing that needs to be noted is that there is still a problem of the possibility of strategy realization during the game between the two parties, that is, the problem of the probability of achieving the strategies of both parties.

\section{Model Assumptions}

When monitoring the pollutant emissions from the papermaking enterprises, this thesis assumes that there are only two participants. One is the government $(G)$. When the government controls the pollutants discharged by papermaking enterprises, most of which will adopt environmental regulations (a means for the government to regulate the negative environmental externalities caused by papermaking 




Figure 1: The game mechanism between the government environmental regulation intensities and the pollutant emissions from papermaking enterprises.

enterprises). However, the government's environmental regulation methods still have differences in their strength. The other side is papermaking enterprises $(E)$. Papermaking enterprises will make strategic choices (choose compliance or violation) according to the government environmental regulation intensities and their own conditions. The following are the assumptions of this thesis.

Assumption 1. There is a big difference between the government $(G)$ and the papermaking enterprises $(E)$ in terms of information acquisition, environmental awareness, selfinterest, and ways of thinking. It is precisely because of this information asymmetry and the deviation of cognitive ability that both parties have bounded rationality. That is to say, during the game, both parties will adjust their own strategies according to the changes of information, the other's choices, and their own income, so as to maximize their own interests.

Assumption 2. When the government $(G)$ regulates and supervises the pollutant emissions from papermaking en-

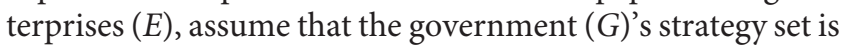
strong and weak regulation, and the strategy set of the papermaking enterprise $(E)$ is compliance and noncompliance. Assuming the probability that the government chooses strong regulation and weak one is $x$ and $1-x$ and the probability that the papermaking enterprise $(E)$ chooses compliant and noncompliant one is $y$ and $1-y$. (Both $x$ and $y$ are probabilities and both are functions of time $t$.)

Assumption 3. The government $(G)$ will also invest a certain amount of cost when regulating the pollutant emissions from papermaking enterprises $(E)$. When the environmental regulation's intensity is greater, the cost is $c_{G 1}$. When the environmental regulation's intensity is weaker, the cost is $c_{G 2}$, and the cost of the government's stronger environmental regulations is less than that of lesser environmental regulations. Although the government $(G)$ has adopted different environmental regulation intensities, the successful probability of the two different strategies is also inconsistent. Therefore, supposing the successful probability that the government $(G)$ adopts strong environmental regulations is $\alpha$, and the government $(G)$ adopts weak environmental regulations and the successful probability is $\beta$. In addition, the profit after successful government regulations is $\pi_{G 1}$. Because of the nature of the government, the benefits of successful government regulations are significantly less than the costs it has paid. Papermaking enterprises $(E)$ will also choose strategies based on different measures adopted by the government. If the papermaking enterprises $(E)$ adopt compliant strategies for the government's environmental regulations, the papermaking enterprises $(E)$ will pay some costs and assume that the cost is $c_{E}$. At this time, papermaking companies will not only get the benefits of compliance $\pi_{E 1}$. The government $(G)$ will also give them some material or spiritual rewards and suppose that the reward is $\omega_{E}$. If the papermaking enterprise $(E)$ adopts noncompliant strategies against the government's environmental regulations, it will be punished at this time, assuming that the penalty loss is $f_{E}$. Although the papermaking enterprise $(E)$ is punished, its illegal pollutant emissions may bring additional benefits, assuming that the additional benefits are $\pi_{E 2}$. If the government $(G)$ and the papermaking enterprise (E) fail to fulfill their obligations or have not fulfilled their commitments, both parties may be punished by the higher level government, assuming that the penalty loss is $f_{E}$. At this time, the probability of both parties being detected by the superior department as negligence (or reported by other departments) is $\eta$. If the two parties choose not to play the game, the government $(G)$ and the papermaking enterprise (E) will get the normal benefits of $\pi_{G}$ and $\pi_{N}$.

Based on the above assumptions, the game payment matrix between the government $(G)$ and the papermaking enterprise $(E)$ can be obtained. For details see Table 1. 


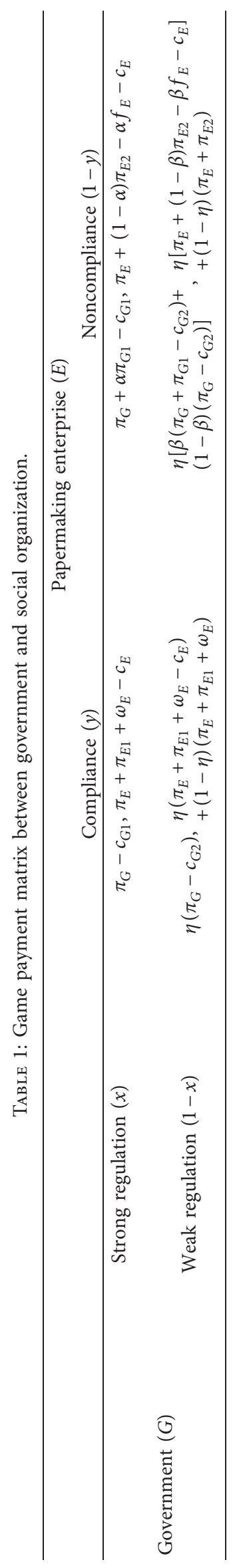




\section{Evolutionary Game Analysis between Government and Papermaking Enterprises}

4.1. Model Establishment and Solution. According to the game payment matrix between the government and papermaking enterprises in Table 1, this thesis assumes that the expected benefits of papermaking enterprises choosing compliant and noncompliant strategies are $u_{E 1}$ and $u_{E 2}$, respectively. When papermaking enterprises choose compliance and noncompliance strategies, their expected benefits are shown in the following formulas:

$$
\begin{aligned}
u_{E 1}= & x\left(\pi_{E}+\pi_{E 1}+\omega_{E}-c_{E}\right)+(1-x) \\
& \cdot\left\{\eta\left(\pi_{E}+\pi_{E 1}+\omega_{E}-c_{E}\right)+(1-\eta)\left(\pi_{E}+\pi_{E 1}+\omega_{E}\right)\right\},
\end{aligned}
$$

$$
\begin{aligned}
u_{E 2}= & x\left(\pi_{E}+(1-\alpha) \pi_{E 2}-\alpha f_{E}-c_{E}\right) \\
& +(1-x)\left\{\eta\left[\pi_{E}+(1-\beta) \pi_{E 2}-\beta f_{E}-c_{E}\right]\right. \\
& +(1-\eta)\left(\pi_{E}+\pi_{E 2}\right)
\end{aligned}
$$

At this point, the average expected benefits of papermaking enterprises choosing compliance and noncompliance strategies are $\overline{u_{E}}=y u_{E 1}+(1-y) u_{E 2}$. The specific expansion is as follows:

$$
\begin{aligned}
\bar{u}_{N}=y\left\{x\left(\pi_{E}+\pi_{E 1}+\omega_{E}-c_{E}\right)+(1-x)\left[\eta\left(\pi_{E}+\pi_{E 1}+\omega_{E}-c_{E}\right)+\right.\right. \\
\left.\left.(1-\eta)\left(\pi_{E}+\pi_{E 1}+\omega_{E}\right)\right]\right\}+(1-y)\left\{\left[x\left(\pi_{E}+(1-\alpha) \pi_{E 2}-\alpha f_{E}-c_{E}\right)\right]\right. \\
\left.+(1-x)\left\{\eta\left[\pi_{E}+(1-\beta) \pi_{E 2}-\beta f_{E}-c_{E}\right]+(1-\eta)\left(\pi_{E}+\pi_{E 2}\right)\right\}\right\} .
\end{aligned}
$$

In the same way, this thesis assumes that the expected benefits of the government's choice of strong regulation strategies and weak ones are $u_{G 1}$ and $u_{G 2}$, respectively, and its expected benefits are shown in following formulas:

$$
\begin{aligned}
u_{G 1}= & y\left(\pi_{G}-c_{G 1}\right)+(1-y)\left(\pi_{G}+\alpha \pi_{G 1}-c_{G 1}\right), \\
u_{G 2}= & y\left[\eta\left(\pi_{G}-c_{G 2}\right)\right]+(1-y)\left[\eta \left[\beta\left(\pi_{G 1}+\pi_{G}-c_{G 2}\right)\right.\right. \\
& \left.\left.+(1-\beta)\left(\pi_{G}-c_{G 2}\right)\right]\right] .
\end{aligned}
$$

At this time, the average expected benefits of the government choosing strong regulation strategies and weak ones are $\overline{u_{G}}=x u_{G 1}+(1-x) u_{G 2}$, The specific expansion is as follows:

$$
\begin{aligned}
\overline{u_{G}}= & x\left[y\left(\pi_{G}-c_{G 1}\right)+(1-y)\left(\pi_{G}+\alpha \pi_{G 1}-c_{G 1}\right)\right] \\
& +(1-x)\left[y \left[\eta\left(\pi_{G}-c_{G 2}\right)+(1-y)\right.\right. \\
& \left.\cdot\left[\eta\left[\beta\left(\pi_{G 1}+\pi_{G}-c_{G 2}\right]+(1-\beta)\left(\pi_{G}-c_{G 2}\right)\right]\right]\right]
\end{aligned}
$$

According to the principle of the Malthusian dynamic equation, the dynamic equation of the replication of the strategy interaction between the government and the papermaking enterprises can be obtained. The specific forms of the dynamic equation of the replication of the two sides of the game are shown in the following formulas:

$$
\begin{aligned}
\frac{\mathrm{d} x}{\mathrm{~d} t}= & x\left(u_{G 1}-\bar{u}_{G}\right)=x(1-x)\left[y\left(\eta \beta \pi_{G 1}-\alpha \pi_{G 1}\right)\right. \\
& \left.-(\eta \beta-\alpha) \pi_{G 1}-(\eta-1) \pi_{G}+\eta c_{G 2}-c_{G 1}\right], \\
\frac{\mathrm{d} y}{\mathrm{~d} t}= & y\left(u_{E 1}-\bar{u}\right)=y(1-y)\left[x(\alpha-\eta \beta)\left(\pi_{E 2}+f_{E}\right)\right. \\
& \left.+\eta \beta\left(\pi_{E 2}+f_{E}\right)+\pi_{E 1}-\pi_{E 2}+\omega_{E}\right] .
\end{aligned}
$$

Let $(\mathrm{d} x / \mathrm{d} t)=0$ and $(\mathrm{d} y / \mathrm{d} t)=0$. Solving the copy $\mathrm{dy}-$ namic equation, we can get five equilibrium points, respectively, $(0,0),(0,1),(1,0),(1,1)$, and $\left(x^{*}, y^{*}\right)$.

4.2. Stability Analysis. According to the method proposed by Friedman, the evolutionary stability strategy of the game system can be judged according to the local stability of the Jacobian matrix. The Jacobian matrix of the game system in this article is as follows:

$$
J_{e}=\left[\begin{array}{ll}
(1-2 x)\left[y(\eta \beta-\alpha) \pi_{G 1}-\right. & x(1-x)\left(\eta c_{G 2}-(\eta-1) \pi_{G 2}-c_{G 1}\right) \\
\left.(\eta \beta-\alpha) \pi_{G 1}-(\eta-1) \pi_{G}+\eta c_{G 2}-c_{G 1}\right] & (1-2 y)\left[x(\alpha-\eta \beta)\left(\pi_{E 2}+f_{E}\right)+\right. \\
y(1-y)\left[\alpha\left(\pi_{E 2}+f_{E}\right)+\pi_{E 1}-\pi_{E 2}+\omega_{E}\right. & \left.\left.\eta \beta\left(\pi_{E 2}+f_{E}\right)+\pi_{E 1}-\pi_{E 2}+\omega_{E}\right]\right]
\end{array}\right] .
$$

According to the Jacobian matrix above, the determinant $\left(\operatorname{det} J_{e}\right)$ and trace $\left(\operatorname{tr} J_{e}\right)$ can be obtained. The specific expansion is detailed as follows: 


$$
\begin{aligned}
\operatorname{det} J_{e}= & (1-2 x)\left[y(\eta \beta-\alpha) \pi_{G 1}-(\eta \beta-\alpha) \pi_{G 1}-(\eta-1) \pi_{G}+\eta c_{G 2}-c_{G 2}\right] \\
& *(1-2 y)\left[x(\alpha-\eta \beta)\left(\pi_{E 2}+f_{E}\right)+\eta \beta\left(\pi_{E 2}+f_{E}\right)+\pi_{E 1}-\pi_{E 2}+\omega_{E}\right]- \\
& x(1-x)\left(\eta c_{G 2}-(\eta-1) \pi_{G 2}-c_{G 1}\right) * y(1-y)\left[\alpha\left(\pi_{E 2}+f_{E}\right)+\pi_{E 1}-\pi_{E 2}+\omega_{E},\right. \\
\operatorname{tr}_{e}= & (1-2 x)\left[y(\eta \beta-\alpha) \pi_{G 1}-(\eta \beta-\alpha) \pi_{G 1}-(\eta-1) \pi_{G}+\eta c_{G 2}-c_{G 2}\right] \\
& +(1-2 y)\left[x(\alpha-\eta \beta)\left(\pi_{E 2}+f_{E}\right)+\eta \beta\left(\pi_{E 2}+f_{E}\right)+\pi_{E 1}-\pi_{E 2}+\omega_{E}\right] .
\end{aligned}
$$

After solving the above model, the value of each parameter in the partial equilibrium of the system can be obtained. The specific situation is shown in Table 2.

According to Table 2 and the method proposed by Friedman, $\left(x^{*}, y^{*}\right)$ cannot be an ESS, so it only needs to consider the local stability of the remaining four points. The following part will discuss the stability of the equilibrium point in several different situations.

(1) According to the above assumptions, the cost of implementing weaker environmental regulations is greater than the cost of high-strength environmental regulations, namely $c_{G 2}>c_{G 1}$. Moreover, the probability of success of weak environmental regulation is greater than the probability of success of strong environmental regulation, namely $\beta>\alpha$. Let $\mu=\left(\pi_{E 2}-\pi_{E 1}-\omega_{E} / \pi_{E 2}\right)+f_{E}$ and $\varepsilon=\left((\eta-1) \pi_{G}\right.$ $\left.+c_{G 1}-\eta c_{G 2}\right) / \pi_{G 1} \cdot \mu$ represents the profit-loss ratio of the papermaking enterprise, and $\varepsilon$ represents the government's cost-benefit ratio. This part first discusses the strategy choices of both parties when $\mu>\eta \beta>\alpha$ and $\varepsilon>\eta \beta-\alpha>0$. Under this condition, the equilibrium point of the game system can be judged according to the determinant of the Jacobian matrix at the equilibrium point and the sign of the trace. For details, see Table 3.

It can be seen from Table 3 that when $\mu>\eta \beta>\alpha$, the illegal income of papermaking enterprises is greater than the sum of other incomes. In the face of huge profits, papermaking enterprises will take risks and choose illegal pollutant discharge. And at this time, $\eta \beta-\alpha>0$, that is, the product of the probability of a papermaking company being reported for violations and the probability of successful weak environmental regulations is greater than the probability of successful strong environmental regulations, so the government is more inclined to choose weak environmental regulations. Although the government does not want to see this phenomenon, the government hopes to circumvent such violations of paper companies through third-party reports. The game phase diagram is shown in Figure 2. It can be seen from Figure 2 that the willingness of the two sides of the game to choose cooperation is very low at this time.

(2) This section assumes $\eta \beta>\mu>\alpha$ and $\varepsilon>\eta \beta-\alpha>0$. Under this condition, the equilibrium point of the game system can be judged according to the determinant of the Jacobian matrix at the equilibrium point and the sign of the trace. For details, see Table 4.

It can be seen from Table 4 that when $\eta \beta>\mu>\alpha$, the illegal income of the papermaking enterprise is less than the sum of other incomes. At this time, the papermaking enterprise is more inclined to choose compliant pollutant discharge. Moreover, with the increase of government incentives for compliance companies, the probability of papermaking companies' compliance to discharge pollution increases. Because $\eta \beta-\alpha>0$, the government is more inclined to choose weak environmental regulations. The government still hopes to force paper companies to choose compliance strategies through third-party reports. The game phase diagram is shown in Figure 3.

(3) This section assumes that $\eta \beta>\alpha>\mu$ and $\varepsilon>\eta \beta-\alpha>0$. Under this condition, the equilibrium point of the game system can be judged according to the determinant of the Jacobian matrix at the equilibrium point and the sign of the trace. For details, see Table 5 .

It can be seen from Table 5 that when $\eta \beta>\alpha>\mu$, the strategic choices of both parties in the game are consistent with (2) because the illegal income of the papermaking enterprise is less than the sum of other incomes and $\eta \beta-\alpha>0$. The main difference between the two cases is that they have different evolution paths, but the equilibrium points are the same. The game phase diagram is shown in Figure 4.

(4) This section assumes $\mu>\alpha>\eta \beta$ and $\varepsilon<\eta \beta-\alpha<0$. Under this condition, the equilibrium point of the game system can be judged according to the determinant of the Jacobian matrix at the equilibrium point and the sign of the trace. For details, see Table 6.

It can be seen from Table 6 that when $\mu>\alpha>\eta \beta$, the noncompliance revenue of the papermaking enterprise is greater than the sum of other revenues. In this case, there is a high incidence of illegal pollutant discharge by papermaking enterprises. At this time, $\varepsilon<\eta \beta-\alpha<0$, that is, the product of the probability of a papermaking enterprise being reported for violations and the probability of successful weak environmental regulations is less than the probability of successful strong environmental regulations, so the government is more inclined to choose strong 
TABLE 2: Value table of each parameter in partial equalization.

\begin{tabular}{|c|c|c|c|c|}
\hline Equilibrium point & a11 & a12 & a21 & a22 \\
\hline$(0,0)$ & $\begin{array}{l}-(\eta \beta-\alpha) \pi_{G 1}-(\eta-1) \pi_{G} \\
+\eta c_{G 2}-c_{G 1}\end{array}$ & 0 & 0 & $\eta \beta\left(\pi_{E 2}+f_{E}\right)+\pi_{E 1}-\pi_{E 2}+\omega_{E}$ \\
\hline$(0,1)$ & $-(\eta-1) \pi_{G}+\eta c_{G 2}-c_{G 1}$ & 0 & 0 & $-\left[\eta \beta\left(\pi_{E 2}+f_{E}\right)+\pi_{E 1}-\pi_{E 2}+\omega_{E}\right]$ \\
\hline$(1,0)$ & $\begin{array}{l}-\left(-(\eta \beta-\alpha) \pi_{G 1}\right. \\
\left.-(\eta-1) \pi_{G}+\eta c_{G 2}-c_{G 1}\right)\end{array}$ & 0 & 0 & $\alpha\left(\pi_{E 2}+f_{E}\right)+\pi_{E 1}-\pi_{E 2}+\omega_{E}$ \\
\hline $\begin{array}{l}(1,1) \\
\left(x^{*}, y^{*}\right)\end{array}$ & $-\left(-(\eta-1) \pi_{G}+\eta c_{G 2}-c_{G 1}\right)$ & $\begin{array}{l}0 \\
\mathrm{R}\end{array}$ & $\begin{array}{l}0 \\
\mathrm{~T}\end{array}$ & $\begin{array}{c}-\left[\alpha\left(\pi_{E 2}+f_{E}\right)+\pi_{E 1}-\pi_{E 2}+\omega_{E}\right] \\
0\end{array}$ \\
\hline
\end{tabular}

TABle 3: Analysis of partial equilibrium table.

\begin{tabular}{lccc}
\hline Equilibrium point & $\operatorname{det} J_{e}$ & $\operatorname{tr} J_{e}$ & Stability \\
\hline$(0,0)$ & + & - & ESS \\
$(0,1)$ & - & Uncertain & Saddle point \\
$(1,0)$ & - & Uncertain & Saddle point \\
$(1,1)$ & + & + & Unstable \\
\hline
\end{tabular}

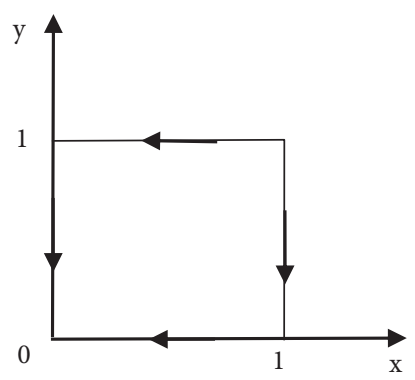

FIGURE 2: Game phase diagram when $\mu>\eta \beta>\alpha$ and $\varepsilon>\eta \beta-\alpha>0$.

TABLe 4: Analysis of partial equilibrium table.

\begin{tabular}{lccc}
\hline Equilibrium point & $\operatorname{det} J_{e}$ & $\operatorname{tr} J_{e}$ & Stability \\
\hline$(0,0)$ & - & Uncertain & Saddle point \\
$(0,1)$ & + & - & ESS \\
$(1,0)$ & - & Uncertain & Saddle point \\
$(1,1)$ & + & + & Unstable \\
\hline
\end{tabular}



FIgURE 3: Game phase diagram when $\eta \beta>\mu>\alpha$ and $\varepsilon>\eta \beta-\alpha>0$.

environmental regulations. The game phase diagram is shown in Figure 5 .

(5) This section assumes $\eta \beta<\mu<\alpha$ and $\varepsilon<\eta \beta-\alpha<0$. Under this condition, the equilibrium point of the
Table 5: Analysis of partial equilibrium table.

\begin{tabular}{lccc}
\hline Equilibrium point & $\operatorname{det} J_{e}$ & $\operatorname{tr} J_{e}$ & Stability \\
\hline$(0,0)$ & - & Uncertain & Saddle point \\
$(0,1)$ & + & - & ESS \\
$(1,0)$ & + & + & Unstable \\
$(1,1)$ & - & Uncertain & Saddle point \\
\hline
\end{tabular}



FIGURE 4: Game phase diagram when $\eta \beta>\alpha>\mu$ and $\varepsilon>\eta \beta-\alpha>0$.

TABLe 6: Analysis of partial equilibrium table.

\begin{tabular}{lccc}
\hline Equilibrium point & $\operatorname{det} J_{e}$ & $\operatorname{tr} J_{e}$ & Stability \\
\hline$(0,0)$ & - & Uncertain & Saddle point \\
$(0,1)$ & + & + & Unstable \\
$(1,0)$ & + & - & ESS \\
$(1,1)$ & - & Uncertain & Saddle point \\
\hline
\end{tabular}

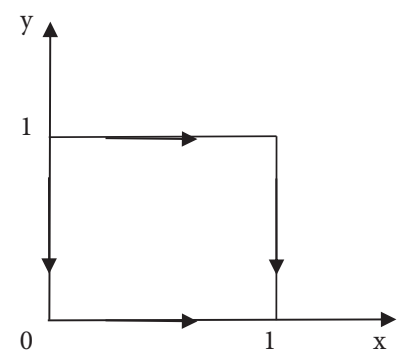

FIGURE 5: Game phase diagram when $\mu>\alpha>\eta \beta$ and $\varepsilon<\eta \beta-\alpha<0$.

game system can be judged according to the determinant of the Jacobian matrix at the equilibrium point and the sign of the trace. For details, see Table 7. 
TABLE 7: Analysis of partial equilibrium table.

\begin{tabular}{lccc}
\hline Equilibrium point & $\operatorname{det} J_{e}$ & $\operatorname{tr} J_{e}$ & Stability \\
\hline$(0,0)$ & - & Uncertain & Saddle point \\
$(0,1)$ & + & + & Unstable \\
$(1,0)$ & - & Uncertain & Saddle point \\
$(1,1)$ & + & - & ESS \\
\hline
\end{tabular}

It can be seen from Table 7 that when $\eta \beta<\mu<\alpha$, as the government's strong environmental regulations' success probability and punishment of companies that violate the regulations increase, paper companies will be more inclined to choose to comply with regulations. Because $\varepsilon<\eta \beta-\alpha<0$, that is, the product of the probability of paper companies being reported for violations and the probability of successful weak environmental regulations is less than the probability of successful strong environmental regulations, so the government is more inclined to choose strong environmental regulations. The game phase diagram is shown in Figure 6.

(6) This section assumes that $\mu<\eta \beta<\alpha$ and $\varepsilon<\eta \beta-\alpha<0$. Under this condition, the equilibrium point of the game system can be judged according to the determinant of the Jacobian matrix at the equilibrium point and the sign of the trace. For details, see Table 8 .

It can be seen from Table 8 that when $\mu<\eta \beta<\alpha$, the illegal income of the papermaking enterprise is less than the sum of other incomes, so it is more inclined to choose to comply with the regulations. Because $\varepsilon<\eta \beta-\alpha<0$, that is, the product of the probability of paper companies being reported for violations and the probability of successful weak environmental regulations is less than the probability of successful strong environmental regulations, so the government is more inclined to choose strong environmental regulations. This situation is consistent with (5), so I will not repeat it here. The game phase diagram is shown in Figure 7.

\section{Evolutionary and Simulation Research}

The above has analyzed the evolutionary game situation of the government's environmental regulation intensities and the pollution discharge of papermaking enterprises under different conditions. This part conducts simulation researches on the above game results. By using numerical simulation methods, it observes how the government environmental regulation intensities affect the strategic choices of papermaking enterprises under different initial values.

(1) Following the above assumptions, when $\mu>\eta \beta>\alpha$ and $\varepsilon>\eta \beta-\alpha>0$, the profits of paper companies from violations are greater than the sum of other benefits, and the product of the probability of being reported for violations and the probability of success in weak environmental regulations is greater than the probability of success in strong environmental

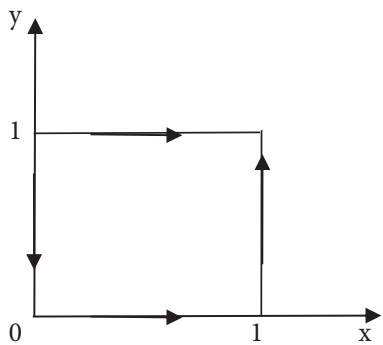

Figure 6: Game phase diagram when $\eta \beta<\mu<\alpha$ and $\varepsilon<\eta \beta-\alpha<0$.

TABLE 8: Analysis of partial equilibrium table.

\begin{tabular}{lccc}
\hline Equilibrium point & $\operatorname{det} J_{e}$ & $\operatorname{tr} J_{e}$ & Stability \\
\hline$(0,0)$ & + & + & Unstable \\
$(0,1)$ & - & Uncertain & Saddle point \\
$(1,0)$ & - & Uncertain & Saddle point \\
$(1,1)$ & + & - & ESS \\
\hline
\end{tabular}

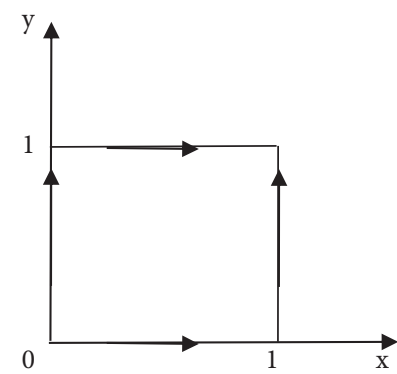

FIGURE 7: Game phase diagram when $\mu<\eta \beta<\alpha$ and $\varepsilon<\eta \beta-\alpha<0$.

regulations. The simulation results are shown in Figure 8. If the illegal revenue of the papermaking enterprises is greater than the sum of other revenues, the papermaking enterprises will take the risk and choose the illegal pollution discharge strategies. If the product of the probability of a papermaking enterprises being reported for violations and the successful probability of weak environmental regulations is greater than the successful probability of strong environmental regulations, the government is more inclined to choose weak environmental regulatory strategies. At this time, the willingness of the two parties to cooperate is zero, and the company is more willing to pursue greater benefits from violations, and the government also hopes to achieve regulation of papermaking enterprises through third-party reporting. While keeping other parameters unchanged, the government will increase the rewards for compliant pollutant companies, which will make the illegal revenue of papermaking enterprises smaller than the sum of other revenues. Therefore, it is more inclined to choose to comply with the regulations. The product of the probability of papermaking enterprises being reported for 


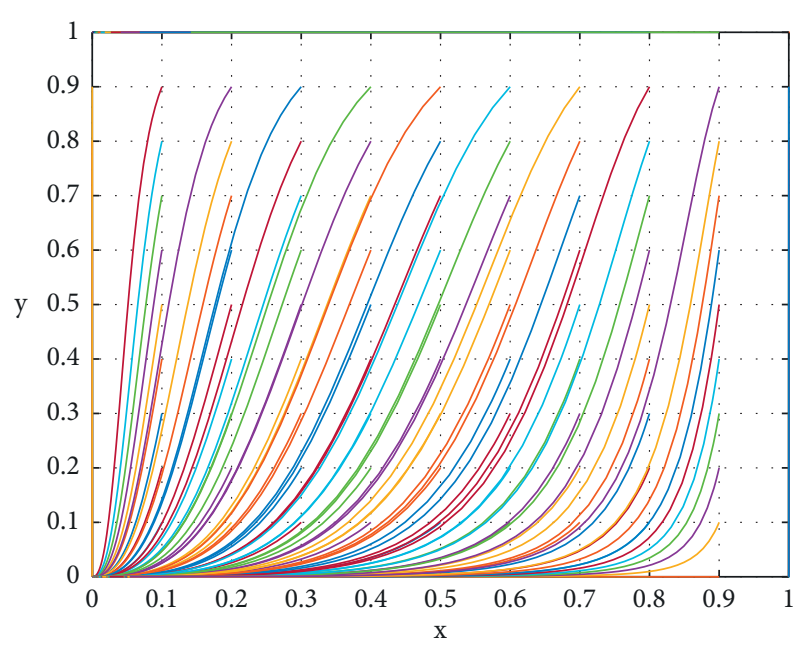

Figure 8: Evolution path when $\mu>\eta \beta>\alpha$ and $\varepsilon>\eta \beta-\alpha>0$.

violations and the probability of successful weak environmental regulations is greater than the probability of successful strong environmental regulations, and the government still chooses weak environmental regulations. The simulation result is shown in Figure 9.

(2) When $\eta \beta>\alpha>\mu$ and $\varepsilon>\eta \beta-\alpha>0$, the evolutionary path of the two sides of the game is similar. While keeping other parameters unchanged, the government will increase the punishment of the illegal pollutant company, which will make the illegal income of the papermaking enterprises smaller than the sum of other income. Therefore, papermaking enterprise is more inclined to comply with regulations. Moreover, under the premise of keeping other parameters unchanged, as the probability of being reported for illegal pollutant discharge by papermaking enterprises increases, it will also make papermaking enterprises choose to comply with the rules for pollutant discharge (the evolution path at this time is similar to Figure 10). The government still chooses weak environmental regulations. The results are shown in Figure 10. When $\mu>\alpha>\eta \beta$ and $\varepsilon<\eta \beta-\alpha<0$, the illegal income of papermaking enterprises is greater than the sum of other incomes, and they are more inclined to choose illegal pollutant discharge. With the increase in the successful probability of government strong environmental regulation and the decline in the cost of strong environmental regulation, the government is more inclined to adopt strong environmental regulation strategies. The results are shown in Figure 11.

(3) When $\eta \beta<\mu<\alpha$ and $\varepsilon<\eta \beta-\alpha<0$, as the government's strong environmental regulations increase the successful probability and the punishment of papermaking enterprises that violate the regulations will increase. At this time, papermaking enterprises are more inclined to choose compliance strategies, while the government is inclined to adopt a strategy

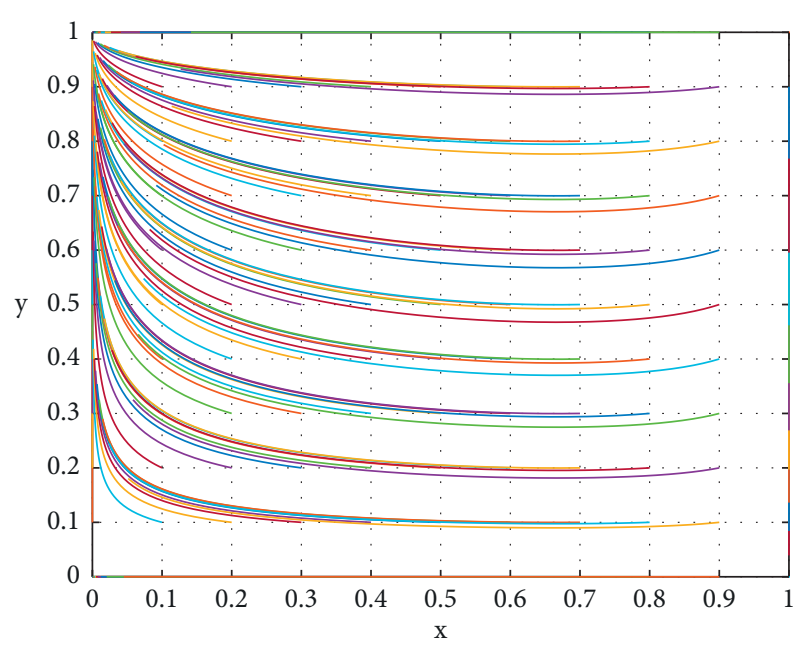

FIGURE 9: Evolution path when $\eta \beta>\mu>\alpha$ and $\varepsilon>\eta \beta-\alpha>0$.



Figure 10: Evolution path when $\eta \beta>\alpha>\mu$ and $\varepsilon>\eta \beta-\alpha>0$.

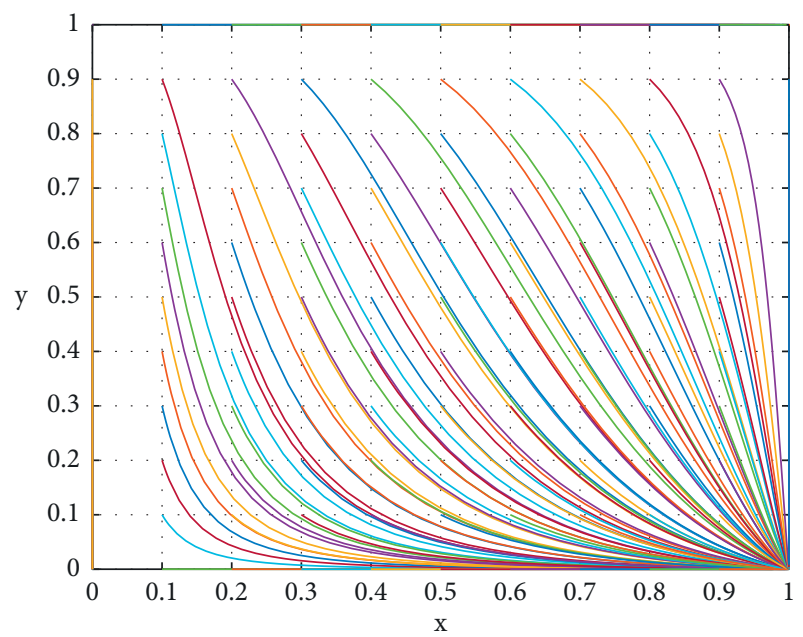

FIGURE 11: Evolution path when $\mu>\alpha>\eta \beta$ and $\varepsilon<\eta \beta-\alpha<0$. 


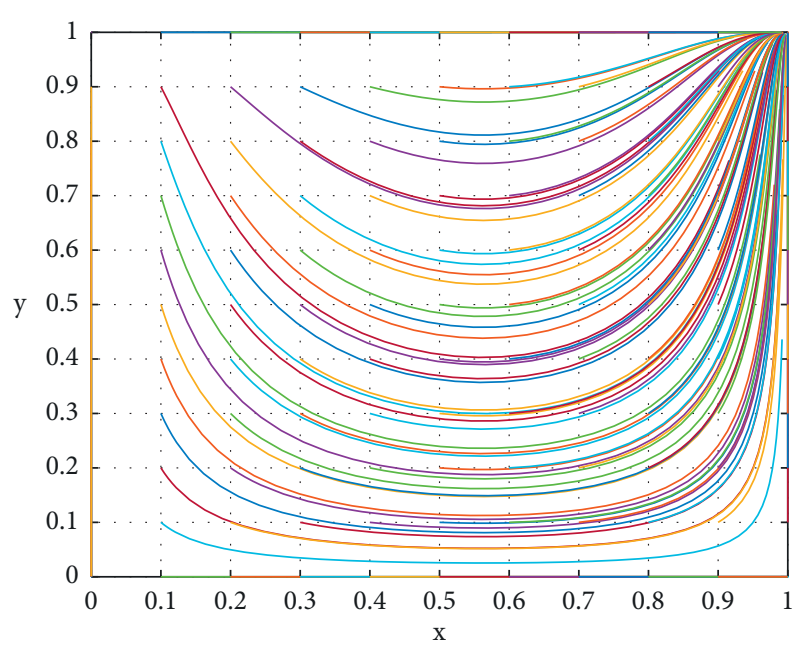

FigURe 12: Evolution path when $\eta \beta<\mu<\alpha$ and $\varepsilon<\eta \beta-\alpha<0$.

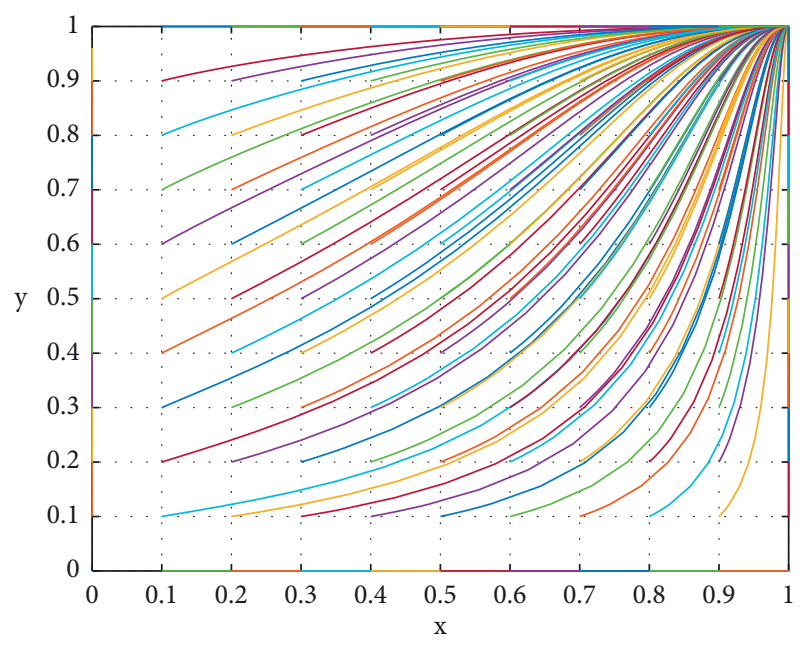

FIGURE 13: Evolution path when $\mu>\alpha>\eta \beta$ and $\varepsilon<\eta \beta-\alpha<0$.

of strong environmental regulation. The specific evolution path is shown in Figure 12. When $\mu<\eta \beta<\alpha$ and $\varepsilon<\eta \beta-\alpha<0$, keep other parameters unchanged. With the increase in government rewards to companies that comply with regulations, papermaking enterprises are more inclined to choose a strategy of compliance and discharge, while the government adopts a strategy of strong environmental regulation. The specific evolution path is shown in Figure 13.

\section{Conclusions and Suggestions}

6.1. Conclusions. Through the above evolutionary game and simulation analysis, it can be seen that the factors that affect the papermaking enterprise's strategic choices mainly include the papermaking enterprise's own income, the probability of third-party detection and reporting, and the government's rewards and punishments for the papermaking enterprise. Specifically, how a papermaking enterprise chooses a pollutant emission strategy depends on its own benefits. If the benefits of violations are far greater than the punishments, they receive after being reported and the rewards for their compliance with pollution discharge, papermaking enterprises will still choose illegal pollution discharge strategies. In addition, the increase in the successful probability of strong environmental regulations does not necessarily guarantee that papermaking enterprises choose compliance emission strategies. Only by increasing the successful probability of strong environmental regulations, taking rewards and punishments and increasing the reporting probability of third-party violations can papermaking companies increase the probability of selecting compliance emission strategies.

6.2. Suggestions. Through the above analysis, we can understand that in the current game between the government and papermaking enterprises, the most important thing is to reduce the enterprises' profits of violation. There are two main ways to achieve this goal. The first one is to promptly discover the noncompliance of papermaking enterprises, and the other one is to increase the punishment for them. Therefore, the government, as the protector of the interests of the majority of people, should and must restrain the speculative emission behaviors of papermaking enterprises. In addition, the higher level government or other social members should also play their own monitoring and supervision roles. Based on this, the author puts forward the following suggestions:

(1) Establish a special pollution monitoring agency.

Establishing a special pollution monitoring agency is one of the main ways to improve the detection of noncompliance pollutant emissions by papermaking enterprises. Of course, it is undeniable that the establishment of the agency is only the first step in pollution monitoring. Because the agency is only a department that accommodates full-time personnel, and it is the people who really investigate, monitor, and manage pollution. Therefore, it is necessary to further improve the professionalism of the personnel of pollution supervision agencies to prevent them from being corroded by sugar-coated shells and eventually cocontaminate with polluting enterprises. The alienation of power lies in the fact that there is no relevant institution to contend with. So it is far from enough to only set up a special pollution supervision institution. It is also necessary to establish an institution or organization that can supervise and evaluate it. This institution or organization is independent from the pollution supervision institution and is not restricted by it. With the mutual checks and balances and mutual supervision, these two jointly promote the greening development of polluting enterprises.

(2) Encourage third parties to monitor and report pollution.

According to the above analysis, the detection or reporting probability of a third party will directly 
affect the strategic choices of papermaking enterprises. Therefore, to make a full supervision, it is necessary to encourage third parties to be independent from the government and papermaking enterprises. The third party can be a higher level government or a social welfare organization. They aim to achieve ecological, economic, and social greening development by fulfilling their obligations and exercising their rights. We have no right to question whether a third party fulfills its obligations or exercises its rights, but we need to work hard to cultivate our own citizenship. We should have the courage to stand up, the valor to speak out, and the means to deal with the things that destroy the ecological environment and other people's welfare.

(3) Increase penalties for polluting enterprises for violations.

Increasing the penalties for illegal pollutant emissions from papermaking enterprises is also a powerful means to reduce their discharge of pollutants and their damage to the ecological environment. As a part of the marketing, papermaking enterprises pursue maximization of profit as their goal from beginning to end. When the income of illegal pollutant emissions is greater than that of compliance pollutants, it is more inclined to choose noncompliant strategies. Therefore, the penalties for noncompliant discharge of pollution should be increased. Once a papermaking enterprise is found to discharge illegally, the government department should use administrative, legal, and economic means to punish it. Moreover, the punishment should be strong, meanwhile, the punishments should be unforgettable, not just superficial. In addition, the prerequisite for increasing penalties is the success of the government's strong environmental regulations or the effectiveness of a third party's reporting of its pollution. Therefore, the three are indispensable. Only when the three work together, it can be possible to minimize pollution and achieve green development.

\section{Discussions}

The practical significance of this article is that the article studies the impact of different intensities of environmental regulations on papermaking enterprises. This kind of research has certain guiding significance for the government to formulate environmental protection policies. In addition, the theoretical significance of this article is that the probability of success of different environmental regulations and the probability of being reported for violations of papermaking enterprises are added to the research process of the article, which further verifies the impact of environmental regulations on corporate pollution.

This thesis uses evolutionary game theory to analyze the impact of different environmental regulation intensities on papermaking enterprises. It also introduces the successful probability of different environmental regulations and the probability of being reported by a third party due to the illegal discharge of papermaking enterprises. However, different local governments and different companies may have different risk preferences. Local governments will implement different environmental policies. And there are still many heterogeneities among companies. The next step can be to incorporate the above contents into the game model.

\section{Data Availability}

The data used to support the findings of this study are included within the Supplementary Materials.

\section{Conflicts of Interest}

The authors declare that there are no conflicts of interest regarding the publication of this article.

\section{Acknowledgments}

The authors thank the National Natural Science Foundation of China for supporting this research. This research was funded by National Natural Science Foundation Youth Project, grant number 71804013.

\section{Supplementary Materials}

The supplementary material contains the values and procedures used in the numerical simulations of this article. (Supplementary Materials)

\section{References}

[1] R. Ran, "Political incentives and local environmental governance under a "pressure system" Comparative Economic \& Social Systems, vol. 29, no. 3, pp. 111-118, 2013.

[2] H. Wang, L. Cai, and W. Zeng, "Research on the evolutionary game of environmental pollution in system dynamics model," Journal of Experimental \& Theoretical Artificial Intelligence, vol. 23, no. 1, 2011.

[3] C. Zhaopeng, "Simulation of haze pollution, regulatory governance and public participation based on evolutionary game analysis," China Population, Resources and Environment, vol. 29, no. 7, pp. 101-111, 2019.

[4] Y. Li and F. Ying, "Government environmental regulation, corporate environmental governance and bank interest rate pricing-theoretical analysis and empirical test based on evolutionary game," Journal of Industrial Technological Economics, vol. 40, no. 11, pp. 99-108, 2020.

[5] S. Bo, X. Du, and H. Taozhen, "Market incentive-oriented environmental regulation and the pattern selection of enterprises' green technology innovation," Soft Science, vol. 35, no. 5 , p. 8, 2021.

[6] X. Sun, W. Wang, J. Pang, X. Liu, and M. Zhang, "Study on the evolutionary game of central government and local governments under central environmental supervision system," Journal of Cleaner Production, vol. 296, no. 3, Article ID 126574, 2021. 
[7] S. Xu, Z. Zhou, and K. Liu, "Multi-evolutionary game research on heavy metal pollution control in soil: based on a thirdparty perspective," Sustainability, vol. 12, 2020.

[8] S. Lindner, Z. Liu, D. Guan, Y. Geng, and X. Li, " $\mathrm{CO}_{2}$ emissions from China's power sector at the provincial level: consumption versus production perspectives," Renewable and Sustainable Energy Reviews, vol. 19, no. Mar, pp. 164-172, 2013.

[9] X. Lang, D. Zhongjie, and C. Jihong, "Evolutionary game of inland shipping pollution control under government co-supervision," Marine Pollution Bulletin, vol. 171, p. 171, Article ID 112730, 2021.

[10] P. Feng, X. Bao, and W. Lin, "Analysis on environmental regulation strategy of local government based on evolutionary game theory," Systems Engineering-Theory \& Practice, vol. 35, no. 6, pp. 1393-1404, 2015.

[11] Y. Ma, Z. Wan, and C. Jin, "Evolutionary game analysis of green production supervision considering limited resources of the enterprise," Polish Journal of Environmental Studies, vol. 30, no. 2, 2020

[12] Q. Peng and Y. Xiao, "Will third-party treatment effectively solve issues related to industrial pollution in China?" Sustainability, vol. 12, 2020.

[13] C. L. Ming and W. W. Ping, "The dynamic evolution of firms' pollution control strategy under graded reward-penalty mechanism," Discrete Dynamics in Nature and Society, vol. 2016, Article ID 7694048, 5 pages, 2016.

[14] A. Js, B. Wz, and B. Bz, "The coordination of stakeholder interests in environmental regulation: lessons from China's environmental regulation policies from the perspective of the evolutionary game theory," Journal of Cleaner Production, vol. 249, 2020.

[15] W. Yang and Y. Yang, "Research on air pollution control in China: from the perspective of quadrilateral evolutionary games," Sustainability, vol. 12, 2020.

[16] C. Zhou, H. Xie, and X. Zhang, "Does fiscal policy promote third-party environmental pollution control in China? an evolutionary game theoretical approach," Sustainability, vol. 11, no. 16, p. 4434, 2019.

[17] L. Xu, Z. Zhou, and J. Du, “An evolutionary game model for the multi-agent co-governance of agricultural non-point source pollution control under intensive management pattern in China," International Journal of Environmental Research and Public Health, vol. 17, no. 7, 2020.

[18] N. Duan and F. Xu, "Collaborative influences of technological innovation capability and government subsidy rate on the stability of eco-innovational cooperation in the chemical industry," Chimica Oggi, vol. 34, no. 6B, pp. 46-52, 2016.

[19] R. Wang, "Operation behavior of offshore mining enterprises based on evolutionary game," Journal of Coastal Research, vol. 94, no. sp1, p. 621, 2019.

[20] W. Duan, C. Li, P. Zhang, and Q. Chang, "Game modeling and policy research on the system dynamics-based tripartite evolution for government environmental regulation," Cluster Computing, vol. 19, no. 4, pp. 2061-2074, 2016.

[21] C. Wang, F. Shi, and C. Yao, "A differential game of industrial pollution management considering public participation," Journal of Mathematics, vol. 2020, Article ID 6621331, 8 pages, 2020.

[22] Y. Yang, D. Tang, and P. Zhang, "Double effects of environmental regulation on carbon emissions in China: empirical research based on spatial econometric model," Discrete Dynamics in Nature and Society, vol. 2020, Article ID 1284946, 12 pages, 2020.
[23] L. Shen and Y. Wang, "Supervision mechanism for pollution behavior of Chinese enterprises based on haze governance," Journal of Cleaner Production, vol. 197, no. 1, pp. 571-582, 2018.

[24] J. Du, Z. Zhou, and L. Xu, "Evolutionary game mechanism on complex networks of green agricultural production under intensive management pattern," Complexity, vol. 2020, Article ID 8541517, 13 pages, 2020.

[25] M. Zhang, H. Li, Y. Song, and C. Li, "Study on the heterogeneous government synergistic governance game of haze in China," Journal of Environmental Management, vol. 248, Article ID 109318, 2019.

[26] M. Zhang and H. Li, "New evolutionary game model of the regional governance of haze pollution in China," Applied Mathematical Modelling, vol. 63, no. NOV, pp. 577-590, 2018.

[27] C. Wang and F. Shi, "An evolutionary game model for industrial pollution management under two punishment mechanisms," International Journal of Environmental Research and Public Health, vol. 16, no. 15, p. 2775, 2019.

[28] P. Kou, Y. Han, and Y. Li, "An evolutionary analysis of corruption in the process of collecting environmental tax in China," Environmental Science and Pollution Research, vol. 28, no. 4, 2021.

[29] R. Xu, Y. Wang, W. Wang, and Y. Ding, "Evolutionary game analysis for third-party governance of environmental pollution," Journal of Ambient Intelligence and Humanized Computing, vol. 10, no. 8, pp. 3143-3154, 2019.

[30] J. Peng, Y. Song, G. Tu, and Y. Liu, "A study of the dual-target corporate environmental behavior (DTCEB) of heavily polluting enterprises under different environment regulations: green innovation vs. pollutant emissions," Journal of Cleaner Production, vol. 297, Article ID 126602, 2021.

[31] Y. Yang and W. Yang, "Does whistleblowing work for air pollution control in China? a study based on three-party evolutionary game model under incomplete information," Sustainability, vol. 11, no. 2, 2019.

[32] H. Wei and Z. Guoqing, "Environmental regulation and pollution haven: an empirical analysis based on panel threshold regression of Chinese provincial data," Economic Theory and Business Management, vol. 28, no. 2, 2017.

[33] Q. Tu and Y. Wang, "New environmental protection taxes in China from the perspective of environmental economics," Discrete Dynamics in Nature and Society, vol. 2021, Article ID 8622081, 10 pages, 2021.

[34] Y. Liu, N. Luo, and S. Wu, "Nonlinear effects of environmental regulation on environmental pollution," Discrete Dynamics in Nature and Society, vol. 2019, Article ID 6065396, 10 pages, 2019.

[35] Z. Yanbo and K. Po, "Environmental regulations, internet penetration rate and enterprise pollution emission," Industrial Economic Review, vol. 9, no. 6, pp. 130-141, 2018. 